\title{
A FRAMEWORK FOR ASSESSING SOCIO- ECONOMIC IMPACT OF COVID-19 AT HOUSEHOLD LEVEL
}

\author{
Khagendra Katuwal ${ }^{1}$, Nirmal Kumar Raut ${ }^{1 *}$, Naveen Adhikari ${ }^{1}$ \\ ${ }^{1}$ Assistant Professor, Central Department of Economics, Tribhuvan University. \\ *Corresponding author: nimsraut@gmail.com
}

\begin{abstract}
The governments across the world have adopted measures to contain the spread of virus which has resulted into restricted economic activities. While economic impacts are diverse and wide spread, the interest in examining impacts at household level is of utmost importance from policy perspectives. This helps monitoring the progress of major socio-economic indicators and make timely and appropriate policy responses. In this context, this perspective paper outlines methodology to be adopted in examining the impacts of COVID-19 in number of household level indicators based on the literatures of impact evaluation. This paper also outlines a framework for identifying key priorities areas with particular reference to Nepal. We propose standard household health production function model with a use of quasi-experimental design as a candidate to examine the impacts at the household level. Likewise, indicators pertaining to poverty, food and nutrition, education, health and labor market are of primary interest with reference to Nepal's development aspirations and trajectory. We expect that this paper will contribute in choosing suitable methodology for assessing impacts at household level and understanding the policy and data context in Nepal.
\end{abstract}

Keywords: COVID-19 - impact - household - health production function development

\section{BACKGROUND}

COVID-19 has resulted into loss of thousands of lives and severe contraction in global economy posing threats to global prosperity, and deeper challenges for revival/recovery. Globally, the confirmed cases and reported deaths are increasing since its first case appeared in December 2019. According to World Health Organization (WHO), there are now 23.4 
million confirmed cases and over 0.8 million reported deaths as of August 23, 2020. Asian Development Bank (ADB) has estimated that global economy will loose $6.4 \%$ to $9.7 \%$ of GDP -equivalent to $\$ 5.8$ trillion to $\$ 8.8$ trillion. Recognizing the seriousness of this pandemic, the International Monetary Fund (IMF) has officially declared global economic recession. This has serious implication to the world economy and particularly more severe in middle and low income countries like Nepal due to limited institutional capacity and resources to deal with such pandemic.

The COVID-19 is creating several unknowns and the world is facing harsh choice between life and livelihood. This pandemic has been a global and its impacts are universal and multi-dimensional in nature. The disproportionate effects, however, are on poor and vulnerable. The World Bank estimated that the pandemic will push 49 million people into extreme poverty in 2020 where about 16 million (32 percent) are in South Asia alone, second to Sub-Saharan Africa. The countries like Nepal where remittances represent a fairly large share of many households' income will have significant impact due to rapid fall in remittance inflow As a consequence,there will be a real threat to Sustainable Development Goal (SDGs) for ending poverty by 2030( Sumner, Hoy, and Ortiz-Juarez, 2020).

While the impacts are multifaceted in nature, understanding it at the household level is crucial for country like Nepal from the perspective of both development trajectory and methodological challenges. The consequences at household level are more prominent on food security, health, education, and labor markets outcomes. The South Asian countries, including Nepal, will face a significant threat on food security and nutrition among children(World Bank, 2020a). The health implications of pandemic are no different than natural disaster and economic shocks (Roberton et al., 2020; Sochas, Channon, and Nam, 2017). Although statistics show that elderly population are disproportionately affected from COVID-19, the physical and mental health problems can be a concern for all age groups. The nutritional intake has seriously been affected due to the pandemic with immediate effect on physical and cognitive development among the children in the short run, and subsequently on labor market outcomes in the long run (Alex-petersen, 2017; Bloom, Canning, and Shenoy, 2012; Bütikofer, Mølland, and Salvanes, 2018; McGovern, Krishna, Aguayo, and Subramanian, 2017). In addition, the pandemic may alter immune responses 
at the maternal-fetal interface thereby eroding the well- being of mothers and infants (Chen et al., 2020; Liu et al., 2020; Zhu et al., 2020).

The implication of COVID-19 on education sector is far reaching causing a significant threat to human capital formation goal of the countries (Almond, 2006; Bleakley, 2010; Percoco, 2016).The World Bank (2020) has estimated that more than 1.5 billion children and youth today are facing some form of school closures. In Nepal nearly 9 million children and youths are affected due to school and university closures (UNESCO,2020). In the face of crisis where the world economy is plunging into recession and supply chains disruption, businesses are either closing or are completely shutting down.

Finally, the labor market impact of the pandemic is also of significant concern. ILO(2020) estimates that 1.6 million to 2.0 million jobs will be disrupted due to the current crisis in Nepal. This job loss will be more crucial for the workers working in the sectors with large informality such as manufacturing, construction, transport and storage, and tourism.

From methodological perspective, the socio-economic impacts of any intended or un-intended changes in the society are analyzed through experimental, quasi-experimental and non-experimental designs. In this study, we discuss the concept of experimental and quasi-experimental designs and suggest an appropriate design to identify the impact of COVID-19 on various socio-economic outcomes.

Available literatures on COVID-19 are mostly focused on assessing the macro or aggregate impacts. Despite upmost importance to assess the impact at household level on number of areas mentioned above, the literature is still limited. Few available micro-level studies too conduct extrapolation and/or simulation based on pre COVID-19 situations. Realizing these facts about limited micro-level studies on COVID-19 and inadequate guidance towards adoption of particular study design in developing countries and other data issues, this paper suggests possible study design, theoretical framework and empirical strategies to be adopted while assessing impacts at household level. It also documents Nepal's development goals and identify key areas and indicators that could be of interest while assessing the impact of COVID-19 in Nepalese context.

The rest of the sections are organized as follows. Section 2 conceptualizes available study designs, reviews a simplistic theoretical 
model in health economics and, proposes an empirical strategy. Section 3 identifies key areas for assessing socio-economic impacts of COVID-19 in Nepal. Section 4 raises some data concerns in Nepal and Section 5 concludes.

\section{METHODOLOGICAL ISSUES AND OPTIONS}

\section{Selecting appropriate study design}

There are broadly two types of study design adopted in impact evaluation literature: experimental and quasi-experimental/observational designs. Sub-sections 2.1.1 and 2.1.2 provides brief discussions on experimental and quasi-experimental study designs and subsequent sections and then assess whether and how they can be used to assess the impact of ill-health and /or COVID-19 on selected outcomes at household levels.

\section{Experimental designs}

Experiments identify the effect of a program or policy by randomly distributing alternative causes over experimental conditions. The main tenet of the design is that the potential confounders are balanced between the treatment and control groups. Consequently, any difference perceived in outcomes of interests between the two groups can then be attributed to the program or the policy. However, in assessing the impact of ill-health, it is quite difficult to follow proper random experiment designs. One major reason is the ethical issue arisen because we cannot assign treatment through 'illness' and conduct an experiment in lab-like setting. Hence, one has to rely on observational or quasi-experimental study designs. However, one should be careful here to note that the experimental designs such as randomized controlled trials (RCT) are quite popular in evaluating the effect of health interventions.

\section{Quasi-experimental study designs}

Quasi-experimental research designs also test whether there is a causal relationship between the intervention and the outcomes. However, unlike experimental designs, quasi-designs lacks random assignment because assignment to treatment and control/comparison is by means of self-selection either by participants themselves or by administrators or by both (Anderson-Cook, 2005). The idea behind the quasi-experimental design is to find a comparison group that is as similar as possible to the treatment group in terms of baseline characteristics and therefore any 
differences in outcome between the two groups is attributed to the program or policy intervention; the comparison group would be a counterfactual of what would have happened to the outcome if there was no treatment.

Several techniques have therefore been evolved in econometrics literature that are quasi-experimental in nature; the widely used techniques are propensity score matching (PSM), regression discontinuity design (RDD), difference-in-difference (DiD), instrumental variable estimation (IV) and, sample selection models. One may also use some combination of these models such as PSM-DiD, IV-DiD. The details on these methods are discussed elsewhere. In analyzing the impact of COVID-19, we can choose either of these models depending upon the type of data collected, timing of data collection in relation to the incidence of pandemic, its quality and reliability and, the sampling design used to collect the data. For example, if data was collected before and after the COVID-19 and that for the areas with high and low/no COVID-19 prevalence, adoption of DiD design would be appropriate.

In case of quasi-experimental design, as discussed above, the assignment between treatment and control is not random. For example, the prevalence of COVID-19 across the unit of analysis (household/community/ village) may not be random. The confounding problem is worse in case of pandemic/epidemic since they normally have high rates of transmission across the unit of analysis thus adding challenges to identification. One can argue the imposition of lockdown that restricts movement of people across communities, villages and, districts and the assumption that social distancing and other safety measures are strictly followed; this would to some extent minimize the rates of transmission. These assumptions, as we all know are shaky, and therefore any attempt to analyze the impact of COVID-19 without considering the problem of selection would result into biased estimates. So it becomes important to ensure that cleaner identification strategy is adopted. The quasi-experimental techniques proposed above may be used to address the problem of self-selection/endogeneity in the prevalence of COVID-19. A basic model for identification is discussed in section 2.3 . 


\section{Theoretical underpinnings}

It is important to understand theoretical underpinnings of health production before delving into the empirical strategies identifying the impact of ill-health on various socio-economic and other outcomes. To begin with, we start by comprehending the reasons why people desire for good health. In other words, why is there a demand-for -health?

Michael Grossman is the pioneer of the demand-for-health model based on which large number of subsequent studies in health economics have been undertaken (Grossman, 1972). Grossman's human capital model, where he includes health along with education, is drawn heavily from the human capital theory of Becker (1964). The main contribution of Grossman is that he distinguishes between health and medical care; the former as an output and hence a fundamental commodity that derives utility while the latter as an input to the production of health. Hence health is demanded because it is both a source of utility and also it affects the total time required for the production of income and wealth. In this paper, we demonstrate a simple demand-for-health model/production function derived largely from the book by Morris et al., (2012).

Let us assume that an individual derives utility from two goods: health capital $(\mathrm{H})$ and a composite of all other fundamental commodities (Z). Hence the utility function can be expressed as:

$$
U=U(H, Z)
$$

It is further assumed positive and diminishing marginal utilities of health and the consumption of all other fundamental commodities i.e. $\frac{\partial u}{\partial H}>0$ and $\frac{\partial^{2} u}{\partial H^{2}}<0$ (and likewise for $\mathrm{Z}$ ). Here, the main tenets is that $\mathrm{Z}$ is a marketable good, whether purchased or self-made while $\mathrm{H}$ is produced by diverse activities and goods. Examples of $\mathrm{H}$ are exercise, medical care, diet, and surgery. $\mathrm{H}$ and $\mathrm{Z}$ are both the sums over time and are weighted by person's time preference. Hence, $\mathrm{H}$ is a weighted sum of healthy number of days that the person enjoys over their life; these healthy days, are in turn, derived from a person's stock of health (HS) implying greater number of healthy days for those with greater stock of health. The health stock at a given time ( $\mathrm{HS}_{\mathrm{t}}$ ), on the other hand, is determined by the stock of health in the immediate past $\left(\mathrm{HS}_{\mathrm{t}-1}\right)$ minus any depreciation in health $\left(d_{t}\right)$ plus any investment made in health during that period $\left(\mathrm{I}_{\mathrm{t}}\right)$. 


$$
H S_{t}=H S_{t-1}-d_{t}+I_{t}
$$

Equation (2) suggests that there may be either net deteriorating or net offsetting effects on health depending upon whether health depreciates more than the investments or vice versa. We can further define production function for $\mathrm{Z}$ and $\mathrm{I}$ which are functions of market goods viz., medical care (M) and all other market goods (X), and time spent either in production of health $\left(T_{H}\right)$ or in producing other goods $\left(T_{O}\right)$. The production function can therefore be expressed as:

$$
\begin{aligned}
& I_{t}=I\left(M_{t}, T_{H t}\right) \\
& Z_{t}=Z\left(X_{t}, T_{O t}\right)
\end{aligned}
$$

Now let us introduce time and budget constraint subject to which an individual will attempt to maximize his/her utility. The individual will spend his/her given timein the production of health $\left(T_{H}\right)$, production of other goods $\left(T_{O}\right)$, working $\left(T_{W}\right)$ and suffering from sickness $\left(T_{S}\right)$ :

$$
T_{t}=T_{H t}+T_{O t}+T_{W t}+T_{S t}
$$

The budget constraint depends upon the amount of income which depends upon the amount of time spent working and the wage rate (W). The expenditure, on the other hand, depends upon the amount spent on purchasing market goods $\mathrm{M}$ and $\mathrm{X}$ and their respective prices, $P_{M}$ and $P_{X}$. Under the assumption that all income is spent, the constraint can be expressed as:

$$
T_{W} W=P_{M} M+P_{X} X
$$

In equation (6), both right hand side and left hand side are regarded as present values since they represent person's lifetime income and expenditure. Hence, they are discounted at the interest rate $r$.

The maximization of utility function given by equation (1) subject to the constraints in equations (5) and (6) and taking the production functions (3) and (4) into account, will lead to equilibrium condition. In equilibrium condition, the individual will equate marginal benefits of health capital and its marginal cost.

There are two types of marginal benefits derived from health investment made; first is the health benefits (consumption benefit) $\left(M B_{H}\right)$ and the second is the monetary returns on investment (investment benefit) 
$\left(M B_{M}\right)$. These benefits are produced from the marginal product of health $\left(M P_{H}\right)$, measured as the number of healthy days generated by one unit of health stock. The consumption benefit can therefore be expressed as the product of $M P_{H}$ and value of healthy days in consumption while investment benefit is the product of $M P_{H}$ and the wage rate. The marginal cost of health capital, on the other hand, is the product of marginal cost of investment in health, the real rate of interest, and the depreciation of health capital (d). The real rate of interest represents the opportunity cost of investment and is calculated as the nominal rate (r) minus the change during the time period in the marginal cost of investment $(\triangle M C I)$. Hence, the equilibrium condition will be then expressed as:

$$
\left.M B_{H t}+M B_{M t}=M C I_{t-1}\left[\left(r-\Delta M C I_{t-1}\right)+d_{t}\right)\right]
$$

Equation (7) is the key result of the Grossman model. It means that one would invest in health up to the point where marginal benefit from investment is equal to its marginal costs.

\section{Empirical strategy}

In this section, we propose a basic model that can be used to identify the impact of COVID-19 on various outcomes which will be discussed in section 3. In explaining equation (8) below, we assume that one-shot nationally representative cross-section data is available; and that it is collected from the survey utilizing appropriate sampling design at some point in the post-COVID-19 situation. Conceptually, however, reduced form of the regression equation expressed in equation (8) would remain the same irrespective of whether an experimental or any form of quasiexperimental design discussed in section 2.1 is chosen.

$$
Y_{i j}=\alpha+\beta_{1} C V D_{j}+\beta_{2} X_{i}+v_{v}+u_{i j}
$$

Where $Y_{i j}$ is the outcome variable of individual $i$ in community $j$, $C V D_{j}$ is a measure of the prevalence of COVID-19 in community $j$ and $X_{i}$ is the set of control covariates. $v_{v}$ is a village fixed effects; this will capture unobserved heterogeneity at the village level and hence control for villagespecific characteristics that normally do not change over time such as the level of health awareness, culture and tradition, level of inequality, health infrastructure etc (Pivovarova \& Swee, 2015). $u_{j i}$ is the stochastic error term which can be clustered at village level to account for any correlation across the households within the village. This is because a village level 
shock may affect all households in the village; hence clustering error term at village level would help report right standard errors. The description of outcome variables and their indicators are provided in section 3 below. The control variables represented by $X_{i}$ should be chosen such that they are exogenous such as socio-economic, demographic and some institutional characteristics. Few examples include age, gender, caste, and education at an individual or household level and some variables that represent the quality and quantity of institutions at the local level. Here, the coefficient $\beta_{1}$ is of interest which yields the effect of COVID-19 on the outcome variable.

Measuring COVID-19 prevalence at community or higher level (village or district) may be appropriate since at household level the risk of transmission is higher than at the community or higher level. In this case, we assume that social distancing and other safety measures are strictly followed and that the lockdown imposition would restrict mobility across communities/villages/districts. Even people move, they need to remain in isolation or in quarantine to ensure that they do not further transmit disease.

We may use two measures of COVID-19 prevalence at community level. One, we can use continuous or an intensive measure of COVID-19 prevalence. In other words, the intensity of its prevalence will be calculated by dividing the number of COVID-19 patients in the community by the size of the population in the area. This will thus identify the impact of COVID-19 in terms of the degree of exposure of the community to the epidemic. Second, we may also divide the community into treatment and control groups as high and low prevalence communities by defining some cut-off point of the prevalence.

For identifying the impact of COVID-19, as we already discussed in section 2.1, it is important that there should be a random assignment of its prevalence across treatment and control groups. Since recent studies show that the prevalence of COVID-19 is higher among old age population and those with pre-existing health conditions (see, for example, Chow et al., 2020; Li et al., 2020), there is a problem of selection in that case. If we can control these and other such observables in equation (8) in $X_{i}$, we can somehow identify the impact of COVID-19. While doing this, we ignore any selection based on unobservable. For example, it may be possible that people who are more prepared to cope might self-select into COVID-19 by engaging in riskier health behavior. Another example may be the health propensity and immunity; an individual with lower immunity 
will have higher chances of transmission and thereby infection. This will cause selection into unobservable; hence, an omitted variable bias may be a concern that will bias the coefficient estimate of COVID-19 prevalence in equation (8).

Hence, depending upon the availability of data and other prerequisites discussed above, we can use any of quasi-experimental techniques. For example, if one has both before-after data and can show sufficient variation in COVID-19 prevalence across communities, it may be proper to use DiD method. If before-after data is longitudinal in nature, one may want to control for household fixed effect or an individual fixed effect instead of controlling village fixed effect as shown in equation (8). This will provide sufficient leverage to the researcher to claim causality since he/she can control for unobserved heterogeneity at household/individual level (example, health propensity of an individual). However, nationally representative longitudinal data are less frequently collected in developing countries due to resource, administrative, and other technical constraints. So, an alternative may be to use repeated cross section data, where we still compare the average outcomes of treatment and control groups before and after the intervention but unit of analysis/observations (e.g., individuals and households) are different. In this case, we cannot control for individual/ household fixed effect. Instead, we can control for village or district fixed effects; this can therefore at least take into account the unobserved heterogeneity at village/district level. In order to further ensure that time varying village or district specific trends (e.g. awareness, inequality, infrastructure etc. that may also change over time) does not render the coefficient estimate of COVID-19 bias, we can control for the trend by including the interaction term of survey year and village/district fixed effects. For a general exposition, we show DiD specification in equation (9) below assuming that before-after repeated cross-section data is available.

$$
Y_{i j t}=\gamma+\gamma_{1} C V D_{j}+\gamma_{2} X_{i t}+\gamma_{3} C V D_{j} * \text { year }_{t}+v_{v}^{*} \text { year }_{t}+v_{v}+\text { year }_{t}+\varepsilon_{i j t}
$$

In equation (9), most of the right hand side and left hand side variables are defined as in equation (8). An interaction term between village and survey year fixed effects $v_{v}{ }^{*}$ year ${ }_{t}$ in above equation represents time varying village specific trends. Further, $\gamma_{3}$ yield the impact of COVID-19.

In case before-after data is not available and data is collected only after the prevalence of COVID-19 as assumed in the exposition of 
equation (1), we may either utilize propensity score matching technique or an instrumental variable approach. In propensity score matching, outcomes of individuals with similar characteristics except exposure to COVID-19 are compared. In case of instrumental variable approach, set of instrument/s have to be chosen which are correlated with $C V D_{j}$ but does not affect the outcome variables thus satisfying the exclusion restriction criteria. We do not delve into discussing these latter two strategies here which are adequately discussed elsewhere.

\section{IDENTIFYING KEY AREAS FOR ASSESSING SOCIO- ECONOMIC IMPACTS OF COVID-19 IN NEPAL}

\section{A framework for Nepal}

We propose that the priorities areas of Nepal for assessing impacts of COVID-19 at household level should be placed in a context of Nepal's progress over the years; and development aspirations for the future. Nepal has documented a satisfactory and comparable progress over its peers in the socio-economic dimensions over the years. For example, the decline in poverty is from $42 \%$ in 1995/96 to $18 \%$ in 2019 (NPC, 2020). Maternal Mortality Rate (MMR) decreased from 553 (per 100,000 live births) in 2000 to 186 in 2017. So Likewise, a decline in Infant Mortality Rate (IMR) from 60 per 1000 live births to 26 in 2018 is noted (World Bank, 2020b). Secondary school enrollment (Gross) has improved from $34 \%$ in 2002 to 80 in 2019 (World Bank, 2020b). Against this backdrop, the Government of Nepal has aspired to position a middle income country status by 2044/45 which aims a significant improvement in number of indicators. However, the COVID-19 has posed challenges in both fronts: to sustain the progress Nepal has achieved during last several decades; and Nepal's development aspirations for making "Prosperous Nepal, Happy Nepali". Therefore, understanding Nepal's development trajectory; and identifying the key sectors for assessing impacts of COVID-19 is crucial.

Figure 1 provides a framework for Nepal. Nepal's aspiration for socio-economic development can be broadly placed within the context of i) Nepal's graduation from LDC countries group by 2024 ii) Key targets set in ongoing fifteenth plan (2018/19-2024/25) iii) Sustainable Development Goals (SDGs) that Nepal has set to achieve by 2030 and, iv) long term goals that Nepal wish to achieve by 2044 (2100 BS). It is important to understand the policy context and indicators since they allow monitoring the progress 
and, more importantly, take note of the possibility of COVID-19 induced reversal of the progress that Nepal has made in socio-economic dimensions. In particular, the areas such as poverty, food and nutrition, education, health and labor market outcomes are of primary importance.

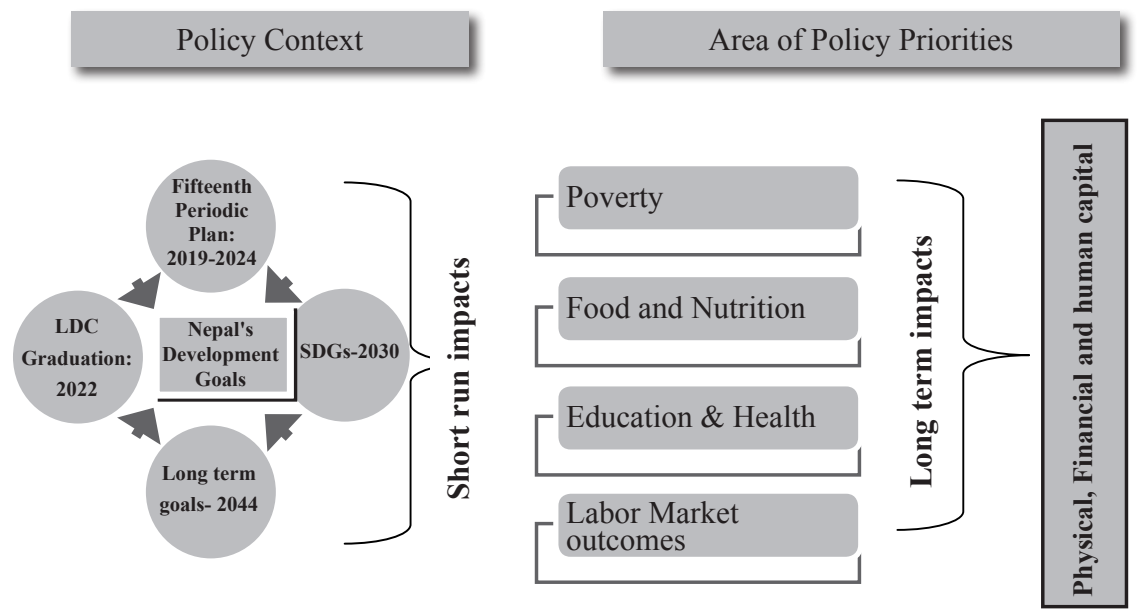

Figure 1: A Framework for identifying key areas and indicators for impact evaluations

Source: Author's construction.

\section{Policy context}

\section{Nepal's graduation from LDC countries group}

Nepal has already fulfilled two of the three criterion of LDC graduation, namely Human Assets Index (HAI) and Economic Vulnerability Index (EVI) while it is still lagging behind in income criterions (GNI). With recent projections of economic growth for short to medium run, it is less likely that Nepal is going to progress on GNI indicator. There is also a possibility that Nepal could experience decelerated progress in some selected indicators within HAI and EVI such as percentage of population undernourished, under five mortality rate, maternal mortality rate, gross second enrollment rate, merchandise export concentration, instability of export of goods and services and instability of agriculture production In this context, we may streamline our exercise of impact analysis to these criterion and indicators that falls within the domain of household level analysis as mentioned in Table 1 below. These indicators might of interest to assess 
the impact of COVID-19 especially with reference to its implication for Nepal's LDC graduation aspirations.

Table 1: Key indicators of LDC graduation

\begin{tabular}{|c|c|c|}
\hline Criterions & Indicators & Measurement \\
\hline \multirow[t]{5}{*}{ Human Assets Index } & Health Index & $\begin{array}{l}\text { Percentage of population } \\
\text { undernourished }\end{array}$ \\
\hline & & Under-five mortality rate \\
\hline & & Maternal mortality rate \\
\hline & Education Index & Gross secondary enrollment ratio \\
\hline & & Adult literacy rate \\
\hline \multirow{6}{*}{$\begin{array}{l}\text { Economic } \\
\text { Vulnerability Index }\end{array}$} & Exposure Index & Population \\
\hline & & Location/Remoteness \\
\hline & & $\begin{array}{l}\text { Economic structure index } \\
\text { Merchandise export concentration } \\
\text { Share of agriculture, forestry and } \\
\text { fishing }\end{array}$ \\
\hline & & $\begin{array}{l}\text { Environment -share of population } \\
\text { in low elevated coast zones }\end{array}$ \\
\hline & Shock Index & $\begin{array}{l}\text { Trade shock-Instability of exports } \\
\text { of goods and services }\end{array}$ \\
\hline & & $\begin{array}{l}\text { Natural shock } \\
\text { Victims of natural disasters } \\
\text { Instability of agriculture production }\end{array}$ \\
\hline Income Criterion & $\begin{array}{l}\text { GNI Per-capita } \\
\text { (in US \$) }\end{array}$ & \\
\hline
\end{tabular}

Source: Least Developed Countries Profile. United Nations (2020)

Fifteenth Periodic Plan (2019/20-2023/24)

Government of Nepal, on its fifteenth periodic plan (2019/202023/24), has set development priorities to create a foundation for prosperous Nepal by providing affordable modern infrastructures, generate decent employment opportunities, higher value added productivity, and 
ensure high, sustainable and pro-poor economic growth (NPC, 2020). Further, the plan aims at ensuring access to quality education and health, providing healthy and balanced environment, and strengthening federal governance system based on social justice and an accountable public service delivery system. The plan has accordingly set a number of socio-economic targets and indicators as provided in Table 2 which we may choose to assess the impact of COVID-19 in the short to medium run.

Table 2: Key socio-economic indicators of Fifteenth Plan

\begin{tabular}{ll}
\hline Dimension & Indicators \\
\hline Poverty & Headcount ratio \\
& Multi -dimensional poverty index \\
& Underweight children (below five years) \\
Health & Life expectancy \\
& Maternal mortality rate (per 100,000 live births) \\
& Under five child mortality rate (per 1000 live births) \\
& Literacy rate (15 years and more) \\
Education & Adult literacy rate (15-24 years) \\
& Net enrollment rate (Primary: 1-8 classes) \\
& Net enrollment rate (Secondary: 9-12 classes) \\
& Gross enrollment at higher education \\
& Labor force participation rate (15 years plus) \\
Employment in formal sector \\
Labor Market & Labor productivity (in Rs thousand) \\
&
\end{tabular}

Source: Fifteenth Periodic Plan(2019/20-2023/24), National Planning Commission (2020), Government of Nepal

\section{Sustainable development goals 2030}

Nepal has streamlined its medium term developmental goals and priorities with Sustainable Development Goals (SDGs) to be achieved by 2030. The SDGs sets a total 147 national targets within the 16 main goals ranging from eradicating hunger and poverty, creating decent jobs to addressing the issues such as climate change. A set of key socio-economic indicators relevant for assessing impacts at household level are provided in Table 3 which could be the main indicator of interest to examine the impact of COVID-19 in the medium run. 
Table 3: Key targets of sustainable development goals

\begin{tabular}{|c|c|}
\hline Goals & Selected Indicators \\
\hline $\begin{array}{l}\text { 1. Eradicate Extreme } \\
\text { Poverty }\end{array}$ & $\begin{array}{l}\text { Population below } 1.25 \text { US \$ per day } \\
\text { Population below } 1.9 \text { US \$ per day } \\
\text { Population below national poverty line } \\
\text { Multi- dimensional poverty index }\end{array}$ \\
\hline $\begin{array}{l}\text { 2. End Hunger and } \\
\text { achieve food security }\end{array}$ & $\begin{array}{l}\text { Prevalence of under nourishment } \\
\text { Prevalence of stunting for under five children } \\
\text { Prevalence of malnutrition under five years age } \\
\text { children }\end{array}$ \\
\hline $\begin{array}{l}\text { 3. Ensure healthy lives } \\
\text { and promote well-being } \\
\text { for all }\end{array}$ & $\begin{array}{l}\text { Maternal mortality ratio (per } 100000 \text { live births) } \\
\text { Proportion of births attended by Skilled health } \\
\text { personnel(per } 100000 \text { live births) } \\
\% \text { of institutional delivery } \\
\text { Under five mortality rate ( } 1000 \text { live births) } \\
\text { Neo natal rate( } 1000 \text { live births) } \\
\% \text { of children under age } 5 \text { with diarrhea }\end{array}$ \\
\hline $\begin{array}{l}\text { 4. Ensure inclusive } \\
\text { and equitable quality } \\
\text { education }\end{array}$ & $\begin{array}{l}\text { Net enrolment primary education } \\
\text { Youth and adults with technical and vocational } \\
\text { training (in thousands, annual) } \\
\text { Literacy rate ( } 15-24 \text { years) } \\
\text { Human asset index } \\
\text { Gender development index }\end{array}$ \\
\hline $\begin{array}{l}\text { 5. Achieve Gender } \\
\text { Equality }\end{array}$ & $\begin{array}{l}\text { Gender inequality index } \\
\text { Gender empowerment index }\end{array}$ \\
\hline $\begin{array}{l}\text { 6. Ensure availability } \\
\text { and sustainable } \\
\text { management of water } \\
\text { and sanitation for all } \\
\text { 10. Reduced Inequality }\end{array}$ & $\begin{array}{l}\text { Proportion of population using safe drinking water } \\
\text { Access to piped water } \\
\text { Households with improved sanitation } \\
\text { Proportion of population using latrine }\end{array}$ \\
\hline
\end{tabular}

Source: Nepal's Sustainable Goals: Baseline Report, National Planning Commission (2017), Government of Nepal

\section{Nepal's long term vision 2045}

The GoN aspires for a set of ambitious socio-economic goals to be achieved during next 25 years (by FY 2045 or 2100 BS) as its long term vision 2045. The goals and targets are tuned according to slogan of "Prosperous Nepal: Happy Nepali". The government aims to reach middle income country status with per capita income as high as of 12,000 USD- 
nearly 12 fold more than Nepal recently has. The economic policies are aimed to direct towards prosperous, self-reliant socialism oriented economy with equalities in opportunities, healthy, educated, decent and happy Nepali citizens having high living standards. Accordingly, a number of indicators have been put in place to monitor the progress against long term vision. Table 4 presents the key socio-economic indicator envisioned in Nepal's long term vision 2045 (NPC, 2020). Therefore, these indicators could be taken to assess the impacts in longer terms.

Table 4: Key socio-economic indicators envisioned in Nepal's long term goal

\begin{tabular}{ll}
\hline Dimension & Indicators \\
\hline Poverty & Headcount ratio \\
& Multi -dimensional poverty index \\
& Human development index \\
& Gender development index \\
Food and Nutrition & Underweight children (below five years) \\
Health & Life expectancy \\
& Maternal mortality rate (per 100,000 live births) \\
& Under five child mortality rate (per 1000 live births) \\
Education & Literacy rate (15 years and more) \\
& Gross enrollment at higher education \\
Labor Market & Labor force participation rate (15 years plus) \\
& Employment in formal sector
\end{tabular}

Source: Fifteenth Periodic Plan (2019/20-2023/24), National Planning Commission(2020), Government of Nepal

\section{DATA CONCERNS}

Once the key indicators for assessing impacts are identified, it is essential to work with data availability and requirements. The rapid surveys conducted through online and telephone interviews have been widely used during the pandemic. These surveys provide a quick snap of the situation and accordingly suggest the policy responses to be followed. The possible data source, therefore, may include rapid surveys, upcoming national surveys and creation of a panel data. First, as practiced globally, rapid surveys can be conducted to quickly assess the situation. It is found that researchers have been using simulation based exercises to estimate ex-ante impacts, and these exercises are based on number of assumptions. Instead, one can rely on the rapid surveys where the researcher can take 
a sub-sample of already existing data set and compare the outcomes with baseline indicators as discussed in section 3. Second, the upcoming national surveys should try to include questions related to COVID-19 context. The key indicators identified in section 3 are based on national surveys such Nepal Living Standard Surveys (NLSSs) for estimating poverty, Nepal Labor Force Survey (NLFS) for labor market situations and outcomes, Nepal Demographic Health Survey (NDHS) for health related indicators, Multiple Cluster Indicator Surveys for Water, sanitation and hygiene, education and health. According to Central Bureau of Statistics (CBS), the survey work for NLSS IV has been interrupted due to COVID-19; it is therefore advisable to include the COVID section in the survey. Third, one may think of creating separate data set relating to COVID-19. In addition to collecting key indicators discussed above, this will collect the information pertaining to the COVID-19. This can be developed as a longitudinal data set to examine the impacts over the long run.

\section{CONCLUSION}

The COVID-19 pandemic has raised serious economic concerns spanning at both macro and micro levels. The macroeconomic studies help to understand broader picture of the impact of the pandemic. However, only a few attempts have been made in Nepal and elsewhere to identify the impact of COVID-19 at household levels. This paper provides a methodological perspective for the selection of appropriate study design in that context. Likewise, we also identify some priority areas and related indicators for the impact study. The priority areas have been largely drawn from systematic sources such as national plan and other related documents. In order to identify the impact of COVID-19 at household level, we propose standard household health production function for building theoretical model and quasi-experimental design for building empirical model. Hence, depending upon the timing and availability of data, its quality, coverage, and sampling design, it may be appropriate to utilize various underlying techniques of quasi-experimental design such as difference-in-difference, propensity score matching, instrumental variable, sample selection models and regression discontinuity design. So far as the outcomes of interest are concerned, we broadly prioritized poverty, health and education, food and nutrition, and labor market outcomes. These dimensions are identified since they reflect the development aspirations of Government of Nepal. 
It might therefore be useful to build on and contextualize the theoretical and empirical strategies proposed in the paper. Likewise, the impact of COVID-19 can be assessed on identified key policy areas and indicators since they have a direct bearing on the achievement of national developmental goals. This will help monitor the progress of the development indicators and adopt appropriate strategies in a timely manner.

\section{REFERENCES}

Alex-petersen, J. (2017). Long-term effects of childhood nutrition: Evidence from a school lunch reform long-term effects of childhood nutrition : evidence from a school lunch reform (IZA DP No. 11234). IZA Discussion Paper. https://www.iza.org/publications/dp/11234/ long-term-effects-of-childhood-nutrition-evidence-from-a-schoollunch-reform

Almond, D. (2006). Is the 1918 Influenza pandemic over? Long term effects of in Utero Influenza exposure in the post 1940 U.S. population. Journal of Political Economy, 114(4): 672-712. https://doi. org/10.1086/507154.

Anderson-Cook, C. M. (2005). Experimental and quasi-experimental designs for generalized causal inference. Journal of the American Statistical Association, 100: 708. https://doi.org/10.1198/jasa.2005. s22

Becker, G. S. (1964). Human capital: a theoretical and empirical analysis, with special reference to education. The University of Chicago Press (Vol. 24).

Bleakley, H. (2010). Health, human capital, and development. Annual Review of Economics, 2: 283-310. https://doi.org/10.1146/annurev. economics.102308.124436

Bloom, D. E., Canning, D. \& Shenoy, E. S. (2011). The effect of vaccination on children's physical and cognitive development in the Philippines. Applied Economics, 44(21): 2777-2783. https://doi.org/10.1080/0 0036846.2011 .566203 .

Bütikofer, A., Mølland, E., \& Salvanes, K. G. (2018). Childhood nutrition and labor market outcomes: Evidence from a school breakfast program. Journal of Public Economics, 168: 62-80. https://doi. org/10.1016/j.jpubeco.2018.08.008.

Chen, H., Guo, J., Wang, C., Luo, F., Yu, X., Zhang, W., et al. (2020). Clinical characteristics and intrauterine vertical transmission potential of COVID-19 infection in nine pregnant women: a 
retrospective review of medical records. The Lancet, 395(10226): 809-815. https://doi.org/10.1016/S0140-6736(20)30360-3.

Chow, N., Fleming-Dutra, K., Gierke, R., Hall, A., Hughes, M., Pilishvili, T., et al. (2020). Preliminary estimates of the prevalence of selected underlying health conditions among patients with coronavirus disease 2019 - United States, February 12-March 28, 2020. Morbidity and Mortality Weekly Report. https://doi.org/10.15585/ MMWR.MM6913E2.

Grossman, M. (1972). On the concept of health capital and the demand for health. Journal of Political Economy, 80(2): 223-255. https://doi. org/10.1086/259880

ILO. (2020). COVID-19 labour market impact in Nepal. International Labour Organization: International Labour Organization.

Li, H., Wang, S., Zhong, F., Bao, W., Li, Y., Liu, L., et al. (2020). Agedependent risks of incidence and mortality of COVID-19 in Hubei Province and other parts of China. Frontiers in Medicine, 7: 190. https://doi.org/10.3389/fmed.2020.00190

Liu, H., Wang, L. L., Zhao, S. J., Kwak-Kim, J., Mor, G. \& Liao, A. H. (2020). Why are pregnant women susceptible to COVID-19? An immunological viewpoint. Journal of Reproductive Immunology, 139: 103-122. https://doi.org/10.1016/j.jri.2020.103122

McGovern, M. E., Krishna, A., Aguayo, V. M. \& Subramanian, S. V. (2017). A review of the evidence linking child stunting to economic outcomes. International Journal of Epidemiology, 46(4): 11711191. https://doi.org/10.1093/ije/dyx017

Morris, S., Devlin, N. \& Parkin, D. (2012). Economic Analysis in Health Care (2nd). Wiley. https://www.wiley.com/en-np/Economic+Anal ysis + in + Healthcare, +2 nd + Edition-p-9781119951490

National Planning Commission (2020). Fifteenth Plan 2076/77- 2080/81. National Planning Commission. Government of Nepal

Percoco, M. (2016). Health shocks and human capital accumulation: The case of Spanish Flu in Italian regions. Regional Studies, 50(9): 1496-1508. https://doi.org/10.1080/00343404.2015.1039975

Pivovarova, M., \& Swee, E. L. (2015). Quantifying the microeconomic effects of war using panel data: Evidence from Nepal. World Development, 66: 308-321. https://doi.org/10.1016/j. worlddev.2014.08.026

Roberton, T., Carter, E. D., Chou, V. B., Stegmuller, A. R., Jackson, B. D., Tam, Y., et al. (2020). Early estimates of the indirect effects 
of the COVID-19 pandemic on maternal and child mortality in low-income and middle-income countries: a modelling study. The Lancet Global Health, 8(7), e901-e908. https://doi.org/10.1016/ s2214-109x(20)30229-1

Sochas, L., Channon, A. A., \& Nam, S. (2017). Counting indirect crisisrelated deaths in the context of a low-resilience health system: The case of maternal and neonatal health during the Ebola epidemic in Sierra Leone. Health Policy and Planning, 32(3): 32-39. https:// doi.org/10.1093/heapol/czx108

Sumner, A., Hoy, C., \& Ortiz-Juarez, E. (2020). Estimates of the impact of COVID-19 on global poverty. UNUWIDER. https://doi. org/10.35188/UNU-WIDER/2020/800-9

World Bank. (2020a). South asia economic focus, spring 2020 : The cursed blessing of public banks. The World Bank, Washington D.C. https:// doi.org/10.1596/978-1-4648-1566-9

World Bank (2020b). World bank indicators. The World Bank Group, Washington. https://data.worldbank.org/indicator (Accessed: 15.07.2020).

Zhu, H., Wang, L., Fang, C., Peng, S., Zhang, L., Chang, G., et al. (2020). Clinical analysis of 10 neonates born to mothers with 2019nCoV pneumonia. Translational Pediatrics, 9(1): 51. https://doi. org/10.21037/tp.2020.02.06 